\title{
Greenhouse gas abatement costs are heterogeneous between Australian grain farms
}

\author{
Nikki P. Dumbrell ${ }^{1,4}$ - Marit E. Kragt ${ }^{1,2} \cdot$ Elizabeth A. Meier $^{3}$ • Jody S. Biggs ${ }^{3}$. \\ Peter J. Thorburn ${ }^{3}$
}

Accepted: 20 June 2017 / Published online: 19 July 2017

(C) The Author(s) 2017. This article is an open access publication

\begin{abstract}
Globally, agriculture is a significant contributor to greenhouse gas emissions. The environment (e.g., soils and climate) and management influence agricultural greenhouse gas emissions and the potential to reduce emissions. For agriculture to contribute to greenhouse gas abatement in the long term, it is important to identify low-cost mitigation actions that farmers can adopt. It is hypothesized that greenhouse gas abatement potential and the associated costs will differ substantially between environments in Australia. Seven alternative management scenarios were identified as both suitable for adoption across different grain growing environments in Australia and potentially able to provide greenhouse gas abatement. The Agricultural Production Systems Simulator was used to simulate these alternative management scenarios over a 25-year period and analyze the potential for Australian grain farmers, across contrasting environments, to increase soil organic carbon stocks and/or reduce nitrous oxide emissions. This analysis was paired with a whole-farm economic analysis to determine the implications of the different greenhouse gas abatement scenarios on farm profitability. Results
\end{abstract}

Nikki P. Dumbrell

nikki.dumbrell@adelaide.edu.au

1 School of Agricultural and Resource Economics, University of Western Australia, M089/35 Stirling Highway, Crawley, WA, Australia

2 Centre for Environmental Economics and Policy and Institute of Agriculture, University of Western Australia, M089/35 Stirling Highway, Crawley, WA, Australia

3 CSIRO Agriculture and Food, Queensland Bioscience Precinct, 306 Carmody Road, St. Lucia, QLD, Australia

4 Present address: Centre for Global Food and Resources, University of Adelaide, 10 Pulteney St., Adelaide, SA, Australia from case studies in Australia's three main grain growing regions demonstrate that significant heterogeneity exists in the biophysical potential and costs to reduce greenhouse gas emissions across locations. The maximum predicted abatement potential for the case study sites varied from 0.34 to 2.03 metric tons of carbon dioxide equivalents per hectare per year. In most simulations, greenhouse gas abatement came at a cost to farmers ranging from 0.11 Australian dollars (AUD) to more than 300 AUD per metric ton of abated carbon dioxide equivalent. This is the first study to explore the costs of mitigation including multiple greenhouse gases and grain farming case studies across Australia. These findings can inform the future development of effective climate change mitigation policies, which frequently use national default values in their design.

Keywords Bio-economic modeling · Climate change policies - Emissions reduction - Farm economic modeling . Greenhouse gas mitigation $\cdot$ APSIM

\section{Introduction}

Agriculture is a significant contributor to global greenhouse gas (GHG) emissions. While agriculture's share of emissions is relatively low in some countries (e.g., 9-10\% of emissions in Europe and the USA), agriculture is responsible for $16 \%$ of GHG emissions in Australia (Department of the Environment 2016). Broadacre cropping contributes to agricultural GHG emissions mostly through carbon dioxide and nitrous oxide from soils produced through the mineralization of soil carbon and the use of nitrogen-based fertilizers (Dalal et al. 2003; Lal 2004; Luo et al. 2010). Reducing these emissions in a cost-effective way will be important to sustainably mitigate global climate change. Fortunately, changes in 
practices can decrease agricultural GHG emissions and even reduce atmospheric GHG concentrations by sequestering carbon in soils or vegetation (Lal et al. 1998; Smith et al. 2008). Agricultural practices that could mitigate GHG emissions include increasing cropping intensity, reducing soil disturbance, reducing nitrogenous fertilizer rates, or increasing inputs of carbon to the soil (Fig. 1; Dalal et al. 2003; Sanderman et al. 2010; Smith et al. 2008; West and Post 2002).

The agriculture sector has become a target industry for sourcing climate change mitigation. In Australia, novel policy programs have been developed to increase GHG abatement in the agricultural sector. In December 2011, the Australian Government introduced the Carbon Farming Initiative which allowed farmers and land managers to accrue Australian Carbon Credit Units for sequestered carbon or reduced GHG emissions achieved via approved projects (Parliament of the Commonwealth of Australia 2011). One Australian Carbon Credit Unit was credited per metric ton of carbon dioxide equivalent $\left(\mathrm{CO}_{2} \mathrm{e}\right)$ in reduced emissions. Participation in the Carbon Farming Initiative was voluntary. Eligible projects had to demonstrate that emission reductions were measurable and verifiable, resulted from activities that were not already common practice, and were not from activities that were required by law (Parliament of the Commonwealth of Australia 2011). For the period July 2012-July 2014, the Carbon Farming Initiative operated alongside a carbon pricing mechanism that required major polluters to pay $\$ 23$ per metric ton $\mathrm{CO}_{2} \mathrm{e}$ for emissions above a certain threshold. This created a market and value for Australian Carbon Credit Units. In December 2014, the Carbon Farming Initiative was replaced by the Emissions Reduction Fund (Parliament of the Commonwealth of Australia 2014). This fund provides payments for emissions reduction activities across the Australian economy, not just from the land sector. Like the previous policy, emission reductions and participation in the policy are voluntary and eligible

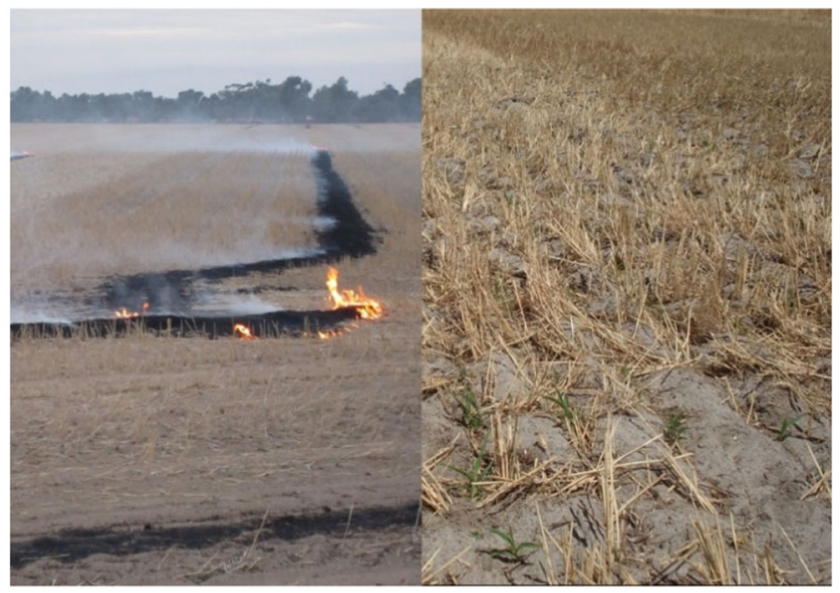

Fig. 1 Stubble burning (left) is a source of greenhouse gas emissions to the atmosphere, while stubble retention (right) is an option for greenhouse gas abatement projects must meet certain criteria. The Emissions Reduction Fund works as a "reverse auction" scheme, where participants can bid with their abatement projects, and quantify the amount and price of abatement they are prepared to deliver. The government enters into contracts with proponents of bids below a benchmark price (not revealed to the public). At the time of writing, three auctions had been held under this policy (in April 2015, November 2015, and April 2016), with an average per metric ton $\mathrm{CO}_{2} \mathrm{e}$ abatement price of $\$ 13.95, \$ 12.25$, and $\$ 10.23$, respectively (Clean Energy Regulator 2016a).

The success of the Carbon Farming Initiative and Emissions Reduction Fund in meeting emissions reduction targets depends on the participation of project proponents and the extent of abatement that can be achieved at low cost. The participation of farmers in either scheme has been low thus far. At 6 May 2016, only 17 of the 348 ERF-contracted abatement projects were based on agricultural management changes (Clean Energy Regulator 2016b). This could be because agricultural abatement costs are higher than the current $\mathrm{CO}_{2}$ e prices paid.

Assessing the potential participation of farmers in climate change mitigation activities requires identification of the abatement costs faced by Australian farmers. Such an analysis will help identify opportunities for GHG abatement and help design effective GHG abatement policies for the agricultural industry. Although a number of studies have addressed the whole-farm economics of GHG abatement, most concentrate on one case study area and/or one GHG (e.g., Crosson et al. 2011; Tang et al. 2016; Kragt et al. 2012; Grace et al. 2010). While an analysis based on one study area can provide insights into the opportunities and costs of abatement in that study region, it cannot identify the biophysical and economic feasibility of abatement across multiple farming environments that vary in soils and climate, which is important when developing nation-wide policies.

This research addresses this gap in current knowledge. Our objective is to demonstrate and discuss the heterogeneity in opportunities to achieve GHG abatement from soils in different grain-growing environments in Australia and the costs of this abatement to grain farmers. We focus on broadacre grain farms, as this sector manages a large area of Australia's soils (31.4 million hectares; Australian Bureau of Statistics 2016) and uses large quantities of nitrogen fertilizer (e.g., NSW DPI 2012; Rural Solutions 2015; Department of Agriculture and Food, Western Australia). Being sources of GHG emissions, more sustainable management of soils and fertilizers offers opportunities for GHG mitigation. Furthermore, $28 \%$ of Australian farmers grow grain (Australian Bureau of Statistics 2012), so outcomes of research for this industry can have an impact for many businesses. We simulate the impacts of different mitigation strategies for three locations across the Australian grain belt. The model results will allow us to illustrate how different farming conditions influence the 
biophysical potential for abatement, as well as abatement costs for farmers. We discuss the implications of differences in opportunities and costs across locations in relation to Australia's emissions reduction policies.

\section{Materials and methods}

\subsection{Case study farms}

To capture the diversity in the Australian grains industry, and the hypothesized heterogeneity of GHG abatement potential and costs across locations, we simulated different potential GHG abatement strategies for grain farms in three locations across the Australian grain belt. The case study farms were located in: the northern wheatbelt of Western Australia, the Wimmera district of Victoria, and the Darling Downs in south-east Queensland (Fig. 2).

These locations represent a wide range of climatic conditions and soil types, leading to differences in the nature of cropping systems. For example, summer dominant rainfall and soils with high plant available water capacity in south-east Queensland enables high-input summer and winter cropping, while relatively low rainfall and sandy soils dominate areas of the Western Australian wheatbelt and restrict farmers to low-input, cereal-dominant winter cropping programs. Variable fertilizer rates were used at the farms depending on crop yield potential and were applied 1 month before sowing (Brigalow) or at sowing and afterwards depending on crop growth stage (other farms).

\subsection{Greenhouse gas abatement scenarios}

We developed a set of potential abatement scenarios in close consultation with farmers in each case study region. Since our focus was on identifying opportunities for GHG abatement from soils on broadacre cropping farms, we simulated management changes that fit within existing broadacre cropping systems. These practices either reduce atmospheric $\mathrm{CO}_{2}$ by increasing soil organic carbon (SOC) stocks and/or reduce nitrous oxide $\left(\mathrm{N}_{2} \mathrm{O}\right)$ emissions from the soil. The baseline practice (reference Scenario S1) consisted of the usual crops and nitrogen fertilizer rates (Fig. 2), with $70 \%$ of their stubble burned about 1 month before sowing the next crop. The remaining scenarios (S2-S8) comprise a number of management practices designed to provide abatement. These scenarios are the same as Scenario S1 except for the following changes:

- S2: Stubble retained instead of burned

- S3: Stubble burnt and 25\% higher fertilizer rate

- S4: Stubble burnt and 25\% lower fertilizer rate

- S5: Stubble retained and 25\% higher fertilizer rate

- S6: Stubble retained and 25\% lower fertilizer rate

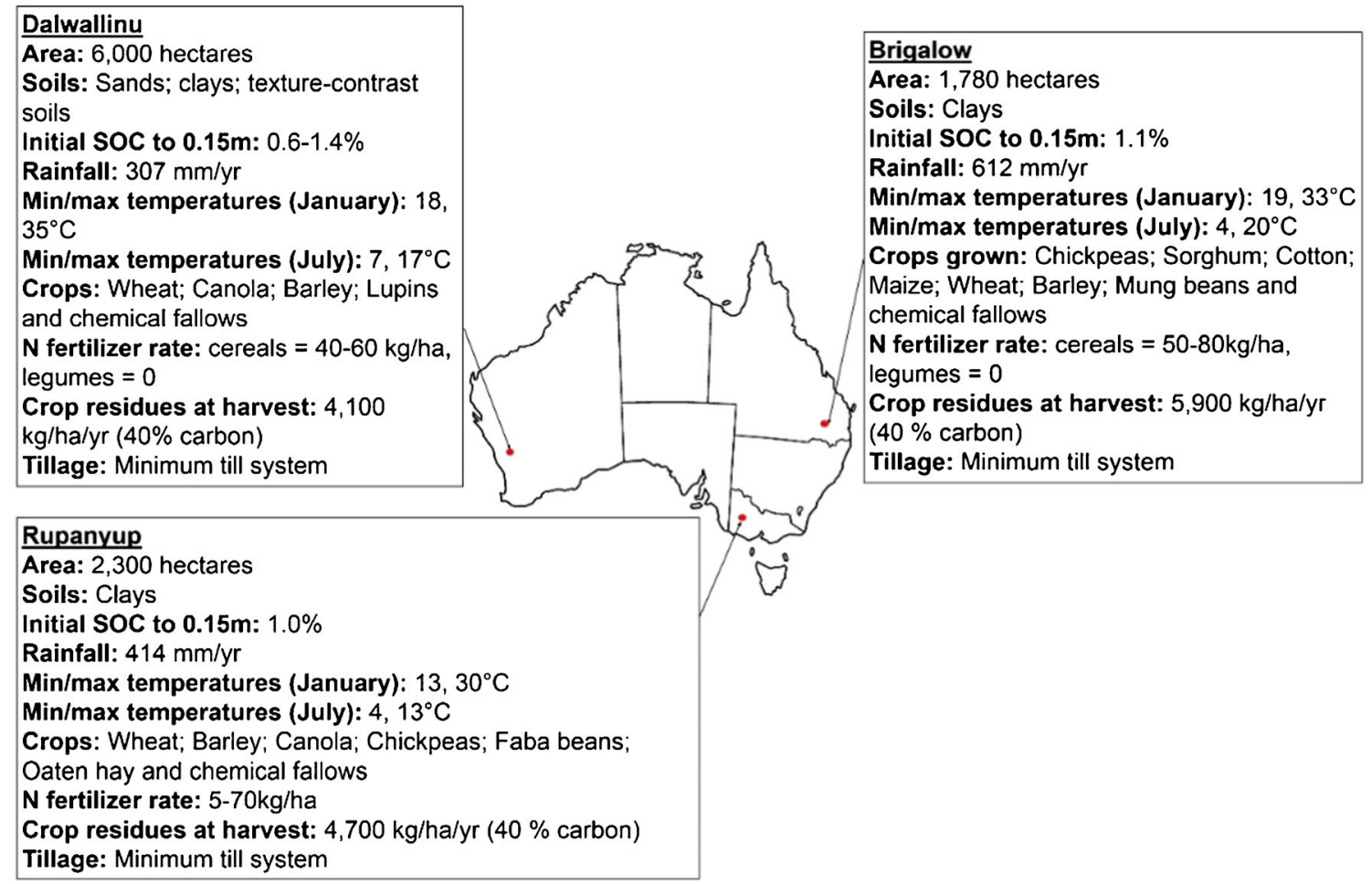

Fig. 2 Case study farm locations, biophysical properties, and usual agronomic practices as described by collaborating local farmer groups and consultants in the study regions 
- S7: Stubble retained and 5 t/ha of feedlot manure (water content $20 \%$, carbon fraction $0.4, \mathrm{C} / \mathrm{N}$ ratio $20: 1$ ) applied every 5 years (fertilizer rates adjusted to account for nutrients in manure)

- S8: Stubble retained and short-term green manure legume planted in place of chemical fallows (increasing cropping intensity)

The GHG emissions produced under each abatement scenario were compared to the emissions under the reference scenario to determine abatement.

\subsection{Simulating abatement potential across different farming systems}

Each scenario was simulated with the Agricultural Production Systems Simulator (APSIM; Holzworth et al. 2014) for each case study farm. For each scenario APSIM was used to predict crop yield, $\mathrm{N}_{2} \mathrm{O}$ emissions, and changes in SOC stocks on each soil type. Changes in $\mathrm{SOC}$ and $\mathrm{N}_{2} \mathrm{O}$ emissions were reported on an annual basis (1 January to 31 December), and crop yield was reported at the time of harvest. The APSIM model has been used extensively to model farming systems represented here (Holzworth et al. 2014), including responses to changed management and for GHG abatement in different environments (e.g., Kragt et al. 2012). The APSIM model was configured with modules for soil nitrogen (APSIM-SoilN; Probert et al. 1998; Thorburn et al. 2010), soil water (APSIM-SoilWat; Probert et al. 1998), soil temperature (APSIM-SoilTemp2, following Campbell 1985), residue (APSIM-SurfaceOM; Probert et al. 1998; Thorburn et al. 2001), and crop growth to represent functions and relationships that influence crop growth, changes in SOC and $\mathrm{N}_{2} \mathrm{O}$ emissions. APSIM-SoilN and APSIM-SoilWat were parameterized with data from representative local soils (Fig. 2) obtained from the APSoil database (Holzworth et al. 2014) to represent the environment of each case study farm. APSIM was also parameterized with local climate data (as per Jeffrey et al. 2001). Crop management information for each scenario (e.g., plant density, sowing depth, and sowing window) was provided through focus group discussions attended by collaborating farmers, farmer groups, and consultants in the case study regions. All crop management and soil nutrient parameters used for the analyses were based on current levels and typical management for the case study regions. Simulations were conducted over a 25 -year time horizon. This time horizon is consistent with many farmers' strategic planning horizon and the permanence requirements in the Emissions Reduction Fund policy (Parliament of the Commonwealth of Australia 2014). Each 25 -year simulation was run using climate data for 10 different starting years, 1956 to 1965 (i.e., the climate data used for the simulations was from 1956 to 1989). This was done to avoid cyclical patterns in the climate data interacting with crop rotations and affecting initial conditions (especially soil carbon) and subsequent changes in soil carbon and $\mathrm{N}_{2} \mathrm{O}$ emissions. The results were then averaged over the starting years to obtain simulation results.

Changes in SOC stock $(0.0-0.3 \mathrm{~m})$ and $\mathrm{N}_{2} \mathrm{O}$ emissions were converted to $\mathrm{CO}_{2} \mathrm{e}$ using conversion factors of 3.67 and 298, respectively (IPCC 2013), and summed to predict net soil-based GHG abatement for each abatement scenario. Tukey's honestly significant difference test was used to identify significant differences $(p<0.05)$ between the abatement scenarios (S2-S8) and the reference scenario (S1) using simulation start years as replicates. All analyses were performed using the R statistical software (v 3.3.1) and the agricolae package (v1.2-4).

\subsection{Calculating the cost of abatement}

The difference in annual operating profit $\left(O P_{n}\right)$ between the reference scenario and each abatement scenario was used to identify the economic impact of changing farm management, in either costs per hectare or per metric ton of $\mathrm{CO}_{2} \mathrm{e}$. Cost per metric ton of $\mathrm{CO}_{2} \mathrm{e}$ is a metric of interest for policy, and the costs per hectare are a common measure of relative profitability used by farmers when considering management changes. Operating profit is equal to the sum of total revenues minus total costs, weighted over soil types $i$ and crops $j$ at each farm $n$ (Eq. (1)):

$O P_{n}=\sum_{i=1}^{I} \sum_{j=1}^{J} a_{i j} \times\left[\left(y_{i j} \times p_{j}\right)-V C_{j}\right]-O C_{n}$

where $a_{i j}$ is the area $a$ of each soil type $i$ and crop $j$ on the farm; revenue is generated by yield $y_{i j}$ multiplied by crop price $p_{j}$; total costs consists of variable costs $V C_{j}$ for each crop $j$ and operating costs $O C_{n}$ that are farm-specific. All prices and costs were expressed in 2015 Australian dollars (\$). Yield $y_{i j}$ was obtained from the APSIM simulations. For crop prices, we took the average farm-gate price for 2010-2014 in each study region, assuming the grain is transported to the nearest port and sold in bulk to the export market (Table 1).

Total costs comprise variable costs $V C_{j}$ for each crop $j$ and operating costs $O C_{n} \cdot V C_{j}$ include seed, fertilizer, chemicals, machinery maintenance and repairs, fuel, lime, gypsum, manure, freight, contractors, casual labor, and crop insurance (Table 1). For the reference scenario, the average $V C$ were $\$ 315, \$ 300$, and $\$ 423 /$ ha/year for the Dalwallinu, Rupanyup, and Brigalow farms, respectively. Fertilizer and chemicals comprise the majority of total variable costs. Some variable costs vary with the abatement scenarios, while others (e.g., crop insurance, machinery repairs and maintenance, and chemical applications) were set at their commonpractice rates for each study area. Operating costs $O C_{n}$ are incurred by the farm regardless of whether a crop is grown. 
Table 1 Crop prices, variable costs, and operating costs used to calculate the operating profit for each scenario at the Dalwallinu, Rupanyup, and Brigalow farms (sources: ABARES 2015a; ABARES 2015b, Rural Solutions 2015, Department of Agriculture and Food Western Australia, collaborating local farmer groups and consultants in the study regions). The machinery budget allows for depreciation and replacement. All dollar figures in 2015 Australian dollars

\begin{tabular}{|c|c|c|c|c|c|c|}
\hline Parameter & Dalwallinu & & Rupanyup & & Brigalow & \\
\hline \multirow{7}{*}{$\begin{array}{l}\text { Crop prices ( } \$ / \text { metric ton, } \\
\text { cotton in } \$ / \text { bale) }\end{array}$} & Wheat & 260 & Wheat & 240 & Wheat & 275 \\
\hline & Barley & 230 & Barley & 230 & Barley & 225 \\
\hline & Canola & 480 & Canola & 490 & Chickpeas & 530 \\
\hline & Lupins & 250 & Chickpeas & 500 & Mung beans & 750 \\
\hline & & & Faba beans & 380 & Sorghum & 210 \\
\hline & & & Oaten Hay & 145 & Maize & 240 \\
\hline & & & & & Cotton & 500 \\
\hline \multirow[t]{6}{*}{ Fertilizer costs ( $\$ /$ metric ton) } & Urea & 607 & Urea & 620 & Urea & 575 \\
\hline & DAP & 837 & MAP & 780 & Starter Z ® & 850 \\
\hline & Agstar Extra ${ }^{\circledR}$ & 757 & & & $\begin{array}{l}\text { Sulfate of } \\
\text { Potash }\end{array}$ & 570 \\
\hline & $\begin{array}{l}\text { Sulfate of } \\
\text { Ammonia }\end{array}$ & 320 & & & & \\
\hline & Superphosphate & 358 & & & & \\
\hline & Muriate of Potash & 716 & & & & \\
\hline \multirow[t]{9}{*}{ Chemical costs $(\$ / \mathrm{ha})$} & Wheat & 109 & Wheat & 89 & Wheat & 88 \\
\hline & Barley & 58 & Barley & 83 & Barley & 83 \\
\hline & Canola & 72 & Canola & 85 & Chickpeas & 64 \\
\hline & Lupins & 48 & Chickpeas & 125 & Mung beans & 60 \\
\hline & Winter fallow & 34 & Faba beans & 138 & Sorghum & 121 \\
\hline & & & Oaten Hay & 40 & Maize & 112 \\
\hline & & & $\begin{array}{l}\text { Winter } \\
\text { fallow }\end{array}$ & 51 & Cotton & 94 \\
\hline & & & & & Summer fallow & 60 \\
\hline & & & & & Winter fallow & 51 \\
\hline $\begin{array}{l}\text { Feedlot manure (\$/metric } \\
\text { ton) }\end{array}$ & 44.50 & & 36.50 & & 30.00 & \\
\hline $\begin{array}{l}\text { Green manure legumes in } \\
\text { fallows, relative to the cost } \\
\text { of fallows }(\$ / \mathrm{ha})\end{array}$ & 135 & & 65 & & 133 & \\
\hline $\begin{array}{l}\text { Farmer owner-manager } \\
\text { wage }\end{array}$ & $\begin{array}{l}\$ 80,000 \text { per full-time } \\
\text { equivalent }\end{array}$ & & $\begin{array}{l}\$ 80,000 \text { per } \\
\text { full-time } \\
\text { equivalent }\end{array}$ & & $\begin{array}{l}\$ 80,000 \text { per full- } t \\
\text { equivalent }\end{array}$ & \\
\hline Overheads & $\$ 94,500$ per year & & $\$ 44,500$ per yea & & $\$ 55,400$ per year & \\
\hline \multirow[t]{3}{*}{$\begin{array}{l}\text { Average annual machinery } \\
\text { budget }\end{array}$} & \multicolumn{2}{|l|}{ Scenario 1-6: $\$ 104,560$} & \multicolumn{2}{|l|}{$\begin{array}{l}\text { Scenario 1-6: } \\
\quad \$ 100,800\end{array}$} & \multirow{3}{*}{\multicolumn{2}{|c|}{ Scenario 1-8: $\$ 110,080$}} \\
\hline & Scenario 7: $\$ 107,560$ & & $\begin{array}{l}\text { Scenario 7: } \\
\quad \$ 101,900\end{array}$ & & & \\
\hline & Scenario 8: $\$ 108,660$ & & $\begin{array}{l}\text { Scenario 8: } \\
\quad \$ 100,800\end{array}$ & & & \\
\hline
\end{tabular}

These include overheads (electricity and phone bills, insurance, advisory and accounting services, administration expenses etc.), the farmer's income, machinery costs, and other capital expenditure.

Operating profit excludes interest and tax payments (Eq. 1). This allows us to compare the costs and benefits of GHG mitigation strategies across farms that operate in different tax environments and have different finance strategies (and thus incur different levels of interest and/or debt). Using operating profit, the differences in profitability across farms is a reflection of the changes made to management for GHG abatement rather than the financial management skills or investment decisions made by the farm owner-manager. Other studies have also used operating profit as a metric to assess the costeffectiveness of GHG abatement (e.g., Adler et al. 2013; Vibart et al. 2015).

\subsection{Sensitivity analysis}

A sensitivity analysis was conducted to determine the costs and benefits of the abatement scenarios under different price conditions. The price scenarios used in the sensitivity analysis capture the scope of cost changes that could be faced by farmers in the case study regions. All variations of costs and 
prices tested in the sensitivity analyses were based on recent observed variability in the market for the respective case study regions. The variability in agricultural commodity prices was represented by running model simulations with crop prices varying from -20 to $+20 \%$ of the value listed in Table 1 . Chemical costs were varied between -20 and $+20 \%$ of the baseline price, and fertilizer prices up to $+20 \%$ to determine the effect of changes in these costs on the relative profitability of the GHG abatement scenarios. To understand the sensitivity (to manure prices) of the relative profitability of Scenario S7 to the baseline scenario, feedlot manure supply and transport costs were varied by altering the feedlot manure price (which includes freight) between -10 and $+20 \%$ of the baseline price. The farm owner/manager wage was varied from $\$ 50,000$ to $\$ 100,000$ per full time equivalent, and the machinery and total operating costs were varied between -20 and $+20 \%$ of the baseline. The operating profit for each GHG abatement scenario determined for each cost or price condition was compared to the baseline price condition scenario and the alternative GHG abatement scenarios.

\section{Results and discussion}

\subsection{Greenhouse gas abatement potential}

The predicted average and maximum abatement relative to the reference scenario varies between scenarios and study sites (Table 2). At the Dalwallinu farm, in the western grain growing region, with sandy soils and a dry climate, all scenarios except those that involved burning stubble (S3 and S4) deliver significant abatement over the 25 -year simulation period. Abatement at the Dalwallinu farm is mostly due to an increase in SOC. The baseline scenario generates little organic matter that can be converted to SOC, so under alternative scenarios where more organic matter is produced and added to the soil, SOC increases. Further, few $\mathrm{N}_{2} \mathrm{O}$ emissions are produced in this dry, sandy soil environment under all scenarios so little abatement can be attributed to a reduction in $\mathrm{N}_{2} \mathrm{O}$ emissions. The maximum average annual abatement achievable at Dalwallinu was 0.77 metric tons $\mathrm{CO}_{2} \mathrm{e}$ per hectare per year (under S8).

At the Rupanyup farm, in south-east grain growing region, with clay soils and a temperate climate, only manuring (S7) and planting green manure legumes in fallows (S8) were predicted to provide significant abatement over 25 years (Table 2). The maximum average annual abatement potential at Rupanyup was delivered by Scenario S8 at 2.03 metric tons $\mathrm{CO}_{2} \mathrm{e}$ per hectare per year.

The greater abatement achievable at the Rupanyup farm relative to the Dalwallinu farm (Table 2) may be driven by two key differences in the properties of clay and sandy soils. Firstly, the sandy soils at the Dalwallinu farm may allow greater SOC loss compared to the clay soils at Rupanyup farm as soil organic matter is exposed to microbial attack without the protection provided by soil aggregates in clay soils. Secondly, water drains more slowly in clay soils so it has greater chance to be available for plant growth before it drains from the
Table 2 Mean and standard deviation (St.dev) of the annual difference in annual abatement and operating profit over 25 years under scenarios $\mathrm{S} 2-\mathrm{S} 8$ relative to reference scenario $\mathrm{S} 1$. We also include the mean contribution of changes in soil organic carbon (SOC) to the mean abatement achieved under each scenario (in metric tons $\mathrm{CO}_{2} \mathrm{e} / \mathrm{ha} /$ year). Positive values represent abatement, an increase in SOC, or increase in operating profits. Negative values represent an increase in greenhouse gas emissions, a decrease in SOC, or decrease in operating profit relative to the reference scenario. Significant differences with reference scenario at $p<0.05$ are indicated by *. All dollar figures in 2015 Australian dollars

\begin{tabular}{|c|c|c|c|c|c|c|c|c|c|}
\hline Scenario & \multicolumn{3}{|c|}{ Dalwallinu } & \multicolumn{3}{|c|}{ Rupanyup } & \multicolumn{3}{|l|}{ Brigalow } \\
\hline \multicolumn{10}{|c|}{$\begin{array}{l}\text { Annual differences in abatement relative to reference scenario } \mathrm{S} 1 \text { and the mean contribution of changes in } \mathrm{SOC} \text { to } \\
\text { net abatement (in metric tons } \mathrm{CO}_{2} \mathrm{e} / \text { ha/year) }\end{array}$} \\
\hline & Mean & St.dev. & $\begin{array}{l}\text { Mean } \Delta \\
\quad \text { SOC }\end{array}$ & Mean & St.dev. & $\begin{array}{l}\text { Mean } \Delta \\
\quad \text { SOC }\end{array}$ & Mean & St.dev. & $\begin{array}{c}\text { Mean } \Delta \\
\quad \text { SOC }\end{array}$ \\
\hline S2 & $0.41^{*}$ & $(0.18)$ & 0.42 & 0.13 & (1.06) & 0.48 & 0.09 & $(0.23)$ & 0.14 \\
\hline $\mathrm{S} 3$ & 0.04 & $(0.05)$ & 0.07 & 0.01 & $(0.10)$ & 0.03 & $-0.20^{*}$ & $(0.11)$ & 0.02 \\
\hline S4 & -0.06 & $(0.06)$ & -0.08 & -0.01 & $(0.11)$ & -0.03 & $0.17 *$ & $(0.15)$ & -0.03 \\
\hline S5 & $0.45^{*}$ & $(0.23)$ & 0.49 & 0.14 & (1.13) & 0.53 & $-0.13^{*}$ & $(0.30)$ & 0.13 \\
\hline S6 & $0.32 *$ & $(0.16)$ & 0.31 & 0.11 & $(0.99)$ & 0.43 & $0.30 *$ & $(0.14)$ & 0.14 \\
\hline S7 & $0.61^{*}$ & $(2.11)$ & 0.64 & $0.36^{*}$ & $(3.47)$ & 0.73 & 0.08 & $(2.22)$ & 0.23 \\
\hline S8 & $0.77 *$ & $(0.54)$ & 0.77 & $2.03 *$ & (1.89) & 1.80 & $0.34 *$ & $(0.54)$ & 0.50 \\
\hline \multicolumn{10}{|c|}{ Annual difference in operating profit relative to reference scenario S1 (in $\$ /$ ha/year) } \\
\hline & Mean & & St.dev. & Mean & & St.dev. & Mean & & St dev. \\
\hline S2 & -5.61 & & $(27.63)$ & -23.25 & & $(76.86)$ & 18.99 & & $(20.53)$ \\
\hline S3 & 11.83 & & $(11.15)$ & 17.33 & & $(28.45)$ & -6.80 & & $(16.35)$ \\
\hline S4 & $-25.03 *$ & & $(14.02)$ & -21.08 & & $(31.79)$ & -17.73 & & (55.89) \\
\hline S5 & $13.72 *$ & & (17.65) & 0.82 & & $(62.62)$ & 8.90 & & (28.88) \\
\hline S6 & $-43.49^{*}$ & & (44.77) & -48.93 & & (98.78) & 6.08 & & (46.10) \\
\hline S7 & -19.08 & & (97.62) & -3.08 & & (115.75) & -17.53 & & (64.29) \\
\hline S8 & $-49.54 *$ & & (32.25) & -143.7 & & (188.89) & $-105.24 *$ & & (65.37) \\
\hline
\end{tabular}


profile. Clay soil also has more potential to store rain received in fallow periods. Thus, with more available water, there is potential to produce bigger plants and returns of crop residues to the soil.

At the Brigalow farm, in the northern grain growing region, reducing nitrogen fertilizer rates and planting green manure crops in fallows (S4, S6, and S8) were predicted to have abatement potential relative to the reference scenario (Table 2). In particular, reducing nitrogen fertilizer rates (S4 and S6) were predicted to achieve significant abatement at Brigalow compared to none or negligible abatement at Dalwallinu and Rupanyup. The greatest average annual abatement achievable at the Brigalow site was 0.34 metric tons $\mathrm{CO}_{2}$ e per hectare per year (under S8).

We further assessed how the year-to-year variability in abatement varied for different scenarios and sites, as indicated by the standard deviation of the mean estimates. Scenario S7 showed the greatest year-to-year abatement variability of all abatement scenarios at all the sites, while variability in abatement was greatest at the Rupanyup farm across scenarios, compared to the other two sites (Table 2). The year-to-year variability is driven by climate conditions, crop rotations, and the definitions of the scenarios. The significant year-to-year variability in abatement/emissions under Scenario S7 is largely due to manure being applied every 5 years, i.e., the abatement outcome in a year when manure is applied is different to the abatement outcomes in the four intervening years. Greater variability at the Rupanyup farm, relative to the other farms, is most likely a result of the interaction between climate conditions and crop rotation. For example, abatement driven by increased SOC stocks was high when a crop was grown and relatively low in winter fallow periods, which were an important feature of the crop rotation at Rupanyup. There were also important tradeoffs in increased SOC and reduced $\mathrm{N}_{2} \mathrm{O}$ emissions at the Rupanyup farm which lead to variable net abatement outcomes. The tradeoff between SOC and $\mathrm{N}_{2} \mathrm{O}$ in net soil-based $\mathrm{GHG}$ abatement is an important contribution of this work as much previous literature has been focused on the potential to achieve abatement by increasing SOC stocks (e.g., Sanderman et al. 2010; Grace et al. 2010; Kragt et al. 2012).

Methane emissions were excluded from this analysis. However, if methane emissions from burning residues (S1, S3, and S4) and from retaining residues were both included in this study, then the emissions from S1 would likely be greater than we simulated and emissions from other scenarios could be unchanged or less than we simulated. Hence, our conclusions regarding the scenarios identified as providing abatement would hold as these scenarios would continue to provide abatement.

These results demonstrate that farmers operating in different climates and with different soil types have different opportunities to provide abatement, and that a uniform set of mitigation strategies will thus lead to different, and potentially perverse, GHG abatement outcomes across locations. This analysis contributes to filling the current gap in knowledge about abatement options in the agricultural sector across multiple environments, as pointed out by Crosson et al. (2011), Tang et al. (2016), and Bustamante et al. (2014). In particular, Crosson et al. (2011) point out that: (1) we cannot use the standard IPCC framework to calculate GHG emissions in regional-level assessments due to variations between countries and default emissions factors, and (2) it is difficult to compare many whole-farm studies as they use different models and data. Whereas Tang et al. (2016) make clear that the literature is dominated by studies that focus on one case study area rather than taking a broader approach. Following this, there are more regional-scale studies needed (Bustamante et al. 2014). The regional or environment-specific information, like that produced from this research, needs to be taken into account when assessing the suitability of policies to achieve GHG abatement on a national scale. Policy makers could consider developing methodologies that are specific to soil types and/or climatic zones. For example, at the time of writing, the addition of manure as an organic fertilizer had not been approved as an abatement method because of potential tradeoffs with $\mathrm{N}_{2} \mathrm{O}$ emissions. Our results confirm that there is a mixed response to manure application across soil types and rainfall zones. At the sandy soil, low rainfall, Dalwallinu farm in Western Australia, manure application was predicted to be a low-cost provider of net soil-based GHG abatement. Clearly, manure application can have beneficial outcomes in specific environments, which could be accounted for in policy development.

\subsection{Cost of abatement}

Most scenarios that deliver abatement decrease farm operating profits relative to the reference scenario (Table 2). This is generally a result of lower crop yields under the alternative scenarios. The only "win-win" scenario (scenario that provided significant abatement and increased profitability relative to the reference scenario) was retaining stubble and increasing nitrogen fertilizer rates (S5) at the Dalwallinu farm, where profits increased by $\$ 13.72$ per hectare per year compared to the reference scenario (Table 2). Increased profitability under Scenario S5 at Dalwallinu was driven by increased crop yields (increased crop revenue). No win-win scenarios were predicted for the Rupanyup or Brigalow farms.

Excluding this win-win scenario, the abatement costs for scenarios that provide significant abatement relative to the reference scenario range from $\$ 8.68$ to $\$ 308.19$ per metric ton of $\mathrm{CO}_{2} \mathrm{e}$, across scenarios and case study farms (Fig. 3). In dollars per hectare per year, the cost to implement these scenarios ranges from $\$ 3.08$ to 143.77 per hectare per year (Table 2). This range of cost estimates is in line with those of 
previous research in similar environments, e.g., Kragt et al. (2012) who explored options to increase soil carbon in the central wheatbelt of Western Australia and Grace et al. (2010) who explored the potential to increase soil carbon in Victoria under different carbon prices. The most costly abatement scenario across regions was predicted at the Brigalow farm under Scenario S8, where abatement would cost \$308.19 per metric ton of $\mathrm{CO}_{2} \mathrm{e}$ (Fig. 3), or $\$ 105.24$ per hectare per year (Table 2). At the Dalwallinu farm, Scenario S2 could provide relatively low-cost abatement at $\$ 13.78$ per metric ton $\mathrm{CO}_{2}$ e. The least cost abatement scenario was Scenario $\mathrm{S} 7$ at the Rupanyup farm, at $\$ 8.68$ per metric ton $\mathrm{CO}_{2} \mathrm{e}$. This low-cost option arises because the use of manure allows some cost savings on fertilizer and does not substantially decrease crop yields. However, as shown by the standard deviations in Fig. 3, the cost of abatement is subject to considerable year-to-year variability, especially for Scenarios S7 and S8. This predicted heterogeneity highlights the need to evaluate multiple case study areas when aiming to draw conclusions about agriculture's potential to contribute to climate change mitigation.

Our cost estimates demonstrate that (excluding win-win scenarios) the average price paid for abatement in the Australian Emissions Reduction Fund auctions to April 2016 (\$12.10 per metric ton of $\mathrm{CO}_{2} \mathrm{e}$; Clean Energy Regulator 2016a) would not have adequately compensated for the decrease in farm profitability (Fig. 3). With the relatively high predicted costs of abatement found in this study, it appears that grain farmers across Australia are unlikely to be competitive in Emissions Reduction Fund auctions if the scope, rules, and prices do not change. If governments are serious about increasing farmers' participation in climate change abatement, then perhaps the agricultural sector would need to be addressed in a separate auction where the benchmark price is higher, or would need to be provided with incentives through different mechanisms.

\subsection{Sensitivity analysis}

The results are most sensitive to changes in fertilizer prices and manure prices, which affect Scenarios S3, S5, and S7 directly and S8 indirectly as scenario S8 uses legumes to replace some nitrogen fertilizer requirements. The results are also sensitive to price and cost changes that differ in their effect upon the abatement scenarios and reference scenarios. Following the model specification, any price or cost that is not constant across scenarios has an impact on relative profitability.

At the Rupanyup farm, increasing fertilizer prices by $20 \%$ changed the relative profitability of scenario S5 (relative to the reference scenario) from $+\$ 0.82 / \mathrm{ha} /$ year under baseline price conditions to $-\$ 0.30 /$ ha/year under higher fertilizer prices. This shows that the profitability of scenarios with higher

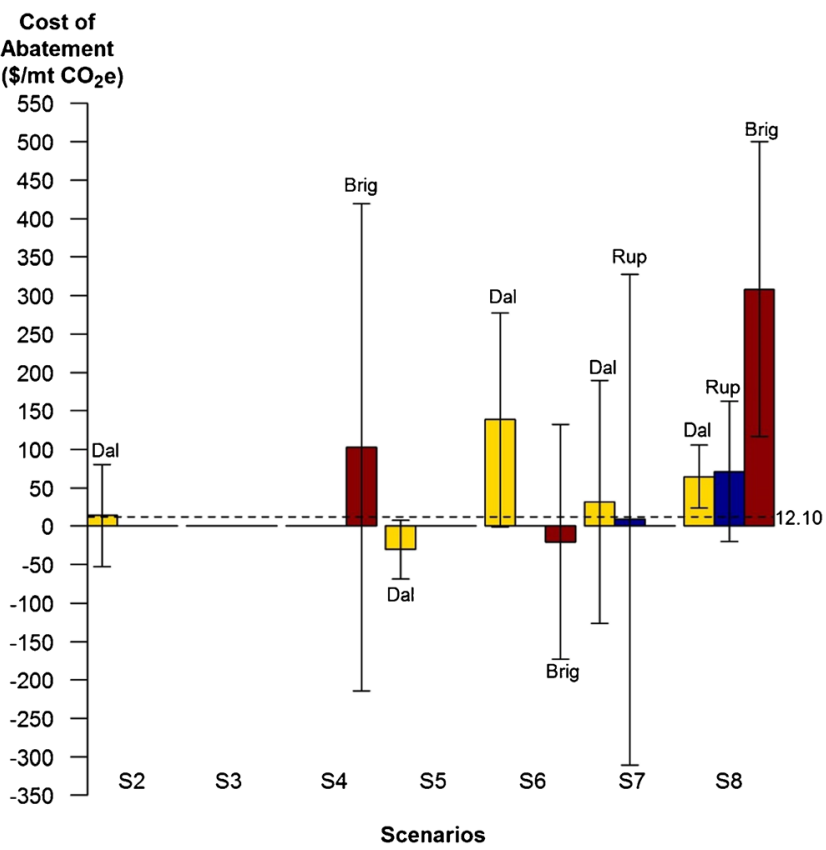

Fig. 3 Variation in the costs of abatement in $\$$ per metric ton of $\mathrm{CO}_{2} \mathrm{e}$ (defined as a change in operating profit and change in $\mathrm{CO}_{2}$ e relative to the reference scenario) for each case study farm: Dalwallinu ( $\mathrm{Dal}$ ), Rupanyup (Rup), and Brigalow (Brig). Only farm-scenario combinations that provide significant abatement (defined as a reduction in average $\mathrm{CO}_{2} \mathrm{e}$ emissions) over the 25-year simulation period are shown. Negative costs of abatement represent increased farm profitability (win-win opportunities to reduce GHG emissions). The error bars show the standard deviation. The dashed line at 12.10 indicates the average price paid for abatement ( $\$$ per metric ton $\mathrm{CO}_{2} \mathrm{e}$ ) across the three Emissions Reduction Fund auctions between April 2015 to April 2016 (Clean Energy Regulator 2016a). All dollar figures in 2015 Australian dollars

fertilizer inputs rely on fertilizer prices being balanced by the revenue received from increases in yield obtained from the increased rate of fertilizer (Table 2). While other price changes affected the absolute operating profit on the farm, they did not alter the relative profitability of the abatement scenarios (relative to the reference scenario) at the Rupanyup farm. At the Dalwallinu and Brigalow farms, none of the price changes tested affected the relative profitability of the GHG abatement scenarios over the 25-year simulation.

Changes in profitability were not statistically significant $(p<0.05)$ compared to the baseline price simulations for any of the farms. Therefore, our conclusions regarding the relative profitability of alternative management practices are shown to hold under a range of reasonable historical prices scenarios. Given this, our results can help farmers understand their relative costs of abatement and demonstrate whether abatement will be competitive in the reverse auction schemes used under Australia's Emissions Reduction Fund. However, it is important to note that this research assumed farmers have access to all required inputs, knowledge, and technologies and did not incur transaction costs involved with gaining access. In reality, not all inputs required for the abatement scenarios 
may be available in the local area (e.g., feedlot manure would require a nearby supplier). Furthermore, there may be transaction costs associated with learning about the new management scenarios and policy schemes. It is also worth commenting on the "current management" scenario used in our analysis. Using stubble burning as a reference, we predicted that retaining crop stubble will typically provide abatement and increase (or not change) operating profits. In reality, changing from stubble burning to complete stubble retention could lead to increased costs for, for example, weed control. Increased input costs and/or transaction costs are likely to increase the estimated costs of GHG abatement on farms.

\section{Conclusion}

We identified the GHG mitigation potential and the costs of abatement at three farms located in the main grain growing regions of Australia. The results show a marked difference in abatement potential and impact on operating profits across case study farms and management practices. Calculating the change in operating profits when adopting potential abatement practices demonstrates that reaching significant climate change abatement will come at a cost to farmers. If farmers' participation in emissions reduction activities is important for reaching emissions reductions targets, the incentives on offer must be commensurate with the costs faced by the agricultural industry.

This research is timely because agriculture has become a target industry for GHG abatement worldwide and because Australia has a national policy designed to compensate farmers (and other businesses) for costs incurred to achieve GHG abatement. The potential costs of agricultural GHG emissions are also important for emission reduction schemes. New Zealand, the USA, Canada, and European Union member states all have emissions reductions targets and carbon trading schemes, but with no obligation for agriculture to participate. As global efforts to reduce emissions must increase, the importance of reducing agricultural emissions will grow. Therefore, it is important to now consider policy instruments that can account for the heterogeneous abatement opportunities and costs in agricultural industries.

\footnotetext{
Acknowledgements Funding for this project was provided by the Australian Government Department of Agriculture and Water Resources through the Carbon Farming Futures Filling the Research Gap program and the Grains Research and Development Corporation and is gratefully acknowledged. Regional data for the study sites were provided though collaboration with the Liebe Group, the Brigalow local farmer group, and Dr. Harm van Rees (Cropfacts Pty Ltd) and is greatly appreciated.
}

Open Access This article is distributed under the terms of the Creative Commons Attribution 4.0 International License (http:// creativecommons.org/licenses/by/4.0/), which permits unrestricted use, distribution, and reproduction in any medium, provided you give appropriate credit to the original author(s) and the source, provide a link to the Creative Commons license, and indicate if changes were made.

\section{References}

ABARES (2015a) AGSURF: farm survey data. Available from: apps.daff.gov.au/AGSURF. Accessed 15 April 2015

ABARES (2015b) Australian crop Report. Report no. 176, December 2015. Australian Bureau of Agricultural and Resource Economics and Sciences, Canberra, ACT

Adler AA, Doole GJ, Romera AJ, Beukes PC (2013) Cost-effective mitigation of greenhouse gas emissions from different dairy systems in the Waikato region of New Zealand. J Environ Manag 131:33-43. doi:10.1016/j.jenvman.2013.09.038

Australian Bureau of Statistics (2012) Australian farming and farmers. Available from: www.abs.gov.au/AUSSTATS/abs@.nsf/Lookup/ 4102.0Main+Features10Dec+2012. Accessed 31 May 2016

Australian Bureau of Statistics (2016) Land Management and Farming in Australia, 2014-15. Available from: http://www.abs.gov.au/ AUSSTATS/abs@.nsf/Lookup/4627.0Main+Features12014-15? OpenDocument. Accessed 23 August 2016

Bustamante M, Robledo-Abad C, Harper R et al (2014) Co-benefits, trade-offs, barriers and policies for greenhouse gas mitigation in the agriculture, forestry and other land use (AFOLU) sector. Glob Chang Biol 20:3270-3290. doi:10.1111/gcb.12591

Campbell GS (1985) Soil physics with basic: transport models for soilplant systems. Elsevier, Amsterdam

Clean Energy Regulator (2016a) Cumulative auction results-April 2015, November 2015 and April 2016. Available from: www. cleanenergyregulator.gov.au/ERF/Auctions-results/april-2016. Accessed 6 May 2016

Clean Energy Regulator (2016b) Emissions Reduction Fund project register. Available from: www.cleanenergyregulator.gov.au/ERF/ project-and-contracts-registers/project-register. Accessed 6 May 2016

Crosson P, Shalloo L, O'Brien D, Lanigan GJ, Foley PA, Boland TM, Kenny DA (2011) A review of whole farm systems models of greenhouse gas emissions from beef and dairy cattle production systems. Anim Feed Sci Technol 166-67:29-45. doi:10.1016/j.anifeedsci. 2011.04.001

Dalal RC, Wang WJ, Robertson GP, Parton WJ (2003) Nitrous oxide emission from Australian agricultural lands and mitigation options: a review. Aust J Soil Res 41(2):165-195. doi:10.1071/SR02064

Department of the Environment (2016) Australia's National Greenhouse Accounts: National Inventory by Economic Sector 2014. Australian Government, Canberra

Grace PR, Antle J, Ogle S, Paustian K, Basso B (2010) Soil carbon sequestration rates and associated economic costs for farming systems of south-eastern Australia. Aust J Soil Res 48(8):720-729. doi: $10.1071 / \operatorname{Sr} 10063$

Holzworth DP, Huth NI, Devoil PG et al (2014) APSIM-evolution towards a new generation of agricultural systems simulation. Environ Model Softw 62:327-350. doi:10.1016/j.envsoft.2014.07. 009

IPCC (2013) In: Stocker TF, Qin D, Plattner G-K, Tignor M, Allen SK, Boschung J, Nauels A, Xia Y, Bex V, Midgley PM (eds) Climate change 2013: the physical science basis. Contribution of working group I to the Fifth Assessment Report of the Intergovernmental Panel on Climate Change. Cambridge University Press, Cambridge, United Kingdom and New York, NY, USA

Jeffrey SJ, Carter JO, Moodie KB, Beswick AR (2001) Using spatial interpolation to construct a comprehensive archive of Australian 
climate data. Environ Model Softw 16(4):309-330. doi:10.1016/ S1364-8152(01)00008-1

Kragt ME, Pannell DJ, Robertson MJ, Thamo T (2012) Assessing costs of soil carbon sequestration by crop-livestock farmers in Western Australia. Agric Syst 112:27-37. doi:10.1016/j.agsy.2012.06.005

Lal R (2004) Agricultural activities and the global carbon cycle. Nutr Cycl Agroecosyst 70(2):103-116. doi:10.1023/B:Fres. $0000048480.24274 .0 \mathrm{f}$

Lal R, Kimble JM, Follett RF, Cole CV (1998) The potential of US cropland to sequester carbon and mitigate the greenhouse effect. Ann Arbor Press, Chelsea

Luo ZK, Wang EL, Sun OJ (2010) Soil carbon change and its responses to agricultural practices in Australian agro-ecosystems: a review and synthesis. Geoderma 155(3-4):211-223. doi:10.1016/j.geoderma. 2009.12.012

NSW DPI (2012) Farm budgets and costs. Available from: www.dpi.nsw. gov.au/agriculture/farm-business/budgets. Accessed 15 April 2015.

Parliament of the Commonwealth of Australia (2011) Carbon credits (carbon farming Initiative) bill, explanatory memorandum. Parliament of the Commonwealth of Australia, Canberra, ACT

Parliament of the Commonwealth of Australia (2014) Carbon farming Initiative amendment bill, explanatory memorandum. Parliament of the Commonwealth of Australia, Canberra, ACT

Probert ME, Dimes JP, Keating BA, Dalal RC, Strong WM (1998) APSIM's water and nitrogen modules and simulation of the dynamics of water and nitrogen in fallow systems. Agric Syst 56(1):1-28. doi:10.1016/S0308-521X(97)00028-0

Rural Solutions (2015) Farm Gross Margins Guide: a gross margin template for crop and livestock enterprises. Available from: www.grdc.
com.au/Resources/Publications/2015/02/2015-Farm-Gross-MarginGuide. Accessed 2 March 2015

Sanderman J, Farquharson R, Baldock J (2010) Soil carbon sequestration potential: a review for Australian agriculture. CSIRO Sustainable Agriculture Flagship, Adelaide

Smith P, Martino D, Cai Z, Gwary D et al (2008) Greenhouse gas mitigation in agriculture. Philosophical Transactions of the Royal Society B-Biological Sciences 363(1492):789-813. doi:10.1098/ rstb.2007.2184

Tang K, Kragt ME, Hailu A, Ma C (2016) Carbon farming economics: what have we learned? J Environ Manag 172:49-57. doi:10.1016/j. jenvman.2016.02.008

Thorburn PJ, Probert ME, Robertson FA (2001) Modelling decomposition of sugar cane surface residues with APSIM-residue. Field Crop Res 70(3):223-232. doi:10.1016/S0378-4290(01)00141-1

Thorburn PJ, Biggs JS, Collins K, Probert ME (2010) Using the APSIM model to estimate nitrous oxide emissions from diverse Australian sugarcane production systems. Agric Ecosyst Environ 136(3-4): 343-350. doi:10.1016/j.agee.2009.12.014

Vibart R, Vogeler I, Dennis S, Kaye-Blake W, Monaghan R, Burggraaf V, Beautrais J, Mackay A (2015) A regional assessment of the cost and effectiveness of mitigation measures for reducing nutrient losses to water and greenhouse gas emissions to air from pastoral farms. J Environ Manag 156:276-289. doi:10.1016/j.jenvman.2015.03.041

West TO, Post WM (2002) Soil organic carbon sequestration rates by tillage and crop rotation: a global data analysis. Soil Sci Soc Am J 66(6):1930-1946. doi:10.2136/sssaj2002.1930 